\section{Some fundamental misconceptions about paleotempestology}

Otvos' letter (this issue) is portrayed as a discussion on our recent paper (Liu et al., 2008) based on a new proxy record of hurricanes and fires from Little Lake, Alabama. However, among the six points he raised, only one (\#5) pertains to our new study. The rest of his letter (\#1-3) is in fact largely a rehash of criticisms (Otvos, 1999, 2002) he had previously leveled towards our original proxy record from nearby Lake Shelby (Liu and Fearn, 1993), to which we have already responded directly and substantively on more than one occasion (Liu and Fearn, 2002; Liu, 2004, p. 35; Liu, 2007a, pp. 127-128). It was Otvos himself who has ignored these responses.

Almost $10 \mathrm{yr}$ after he started questioning the overwash origin of the sand layers in our proxy records (Otvos, 1999, 2002), Otvos is still reiterating the unsupported statement that "alternate modes of deposition during lesser storms may well account for their presence". Over the past decade, a growing list of paleotempestology studies, including many that are supported by the use of a modern analog approach, has confirmed the basic premise that the overwash sand layers occurring in coastal lakes and marshes are a reliable proxy for major hurricanes rather than minor hurricanes or winter storms (Liu and Fearn, 1993, 2000; Liu, 2004; Liu et al., 2008; Donnelly et al., 2001a, 2001b, 2004; Donnelly and Webb, 2004; Scileppi and Donnelly, 2007; Donnelly, 2005; Donnelly and Woodruff, 2007). By using Hurricane Ivan as a modern analog, we have shown that the storm surge associated with this category 3 hurricane caused sand deposition in the southern basins of Little Lake and Middle Lake but not in the center of the larger Lake Shelby (Bianchette, 2007), thus confirming our interpretation (Liu and Fearn, 1993) that the proxy record from the center of Lake Shelby is sensitive to direct hits by catastrophic hurricanes of categories 4 and 5 only. Using another approach, Elsner et al. (2008) have developed a statistical model that quantitatively links the hurricane return period (frequency) with the hurricane return levels (intensities) for the Lake Shelby area using information derived from both the historical record (AD 1851-2005) and the proxy record. Their study has also confirmed that it takes landfalling intense hurricanes with wind speeds of at least $64 \mathrm{~m} \mathrm{~s}^{-1}$ (i.e., middle of the category 4 range) to deposit an overwash sand layer in the center of Lake Shelby.

In another recent study in a backbarrier lagoon in Puerto Rico, Woodruff et al. (2008) applied a simple advective-settling model to constrain the coastal flooding intensities required to transport clastic overwash deposits to various distances behind the barrier. They found that the topmost overwash deposits in the core could be attributed to four or five most intense hurricanes that have struck Puerto Rico since ca. AD 1820. No evidence has been found at this site or elsewhere to support Otvos' conjecture that "minor storms, even rainwash from land also carries (sic) coarse sediment" into backbarrier lakes or estuaries.

Otvos confuses the concept of return period with that of cyclicity. In his letter he repeatedly uses phrases like "600-yr 'superhurricane' cycles" and "supposed evidence for cyclicity" to refer to the main conclusions of our work. He criticizes our Little Lake proxy record for its alleged failure "to document cyclicity". In fact, we never used the word cyclicity in our work. What our proxy records show is that catastrophic hurricanes have a return period of about $300 \mathrm{yr}$ (Otvos is still using an outdated figure of $600 \mathrm{yr}$ derived from our 1993 paper, which has since been updated to $300 \mathrm{yr}$; see Liu and Fearn, 2000; Liu, 2004; Liu et al., 2008), which means that each year the Lake Shelby area has a probability of ca. $0.3 \%$ of being directly struck by a hurricane of category 4 or 5 intensity. We have never stated or implied, as Otvos did, that these "superhurricanes" (another term we never used) struck the Alabama coast every 300 or $600 \mathrm{yr}$ in a cyclical pattern.

Otvos' letter contains several factual errors and misconceptions that reveal that he must have misread or misunderstood our work. Another example is his statement that "Liu's assumption of the 600-yr superhurricane recurrence during a recent 3200-yr 'hyperactive' phase, following prolonged calm was not based primarily on lake deposits but on sand layers dated $4760-2650{ }^{14} \mathrm{C}$ yr BP (Liu and Fearn, 1993)". It should be noted that our hyperactive period is dated from ca. 3800 to 1000 cal yr BP and was followed by a quiet period during the most recent millennium (Liu, 2004); not the "recent 3200-yr hyperactive phase" as Otvos have misconstrued. It is also incomprehensible to us how the 4760 and $2650{ }^{14} \mathrm{C}$ dates that he cites relate numerically to his statement about the "600-yr hyperhurricane recurrence" or the "3200-yr hyperactive phase". Moreover, all the ${ }^{14} \mathrm{C}$ dates from our Lake Shelby cores were obtained from bulk organic sediments encompassing the sand layers (Liu and Fearn, 1993), not from the sand layers themselves as he alleges.

Otvos also misunderstands the results of our phytolith study. Phytoliths, per se, are not our "proposed evidence for hurricanes" as he alleges. What we found in our study is that the phytolith assemblages associated with the sand layers are similar to those that are characteristic of sand dune environments, thus supporting the notion that the materials in the sand layers (which are our proposed evidence for hurricanes) are derived from the sand dunes by overwash processes (Lu and Liu, 2005).

Furthermore, Otvos misrepresents a key finding of our study on hurricane and fire interactions (Liu et al., 2008). He incorrectly attributes to us his own misinterpretation that major fires occur "decades later" (his own emphasis) after a major hurricane strike. A careful reading of our paper will show that we stated unequivocally that "the time interval between the hurricane and fire events cannot be more precisely estimated" due to the sampling resolution of our stratigraphic study, thus "it can be inferred from the sedimentation rate (25 $\mathrm{yr}$ per $\mathrm{cm}$ ) that the major fire occurred within $25 \mathrm{yr}$ of the catastrophic hurricane strike" (Liu et al., 2008, p. 37).

We welcome the recent study by Lambert et al. (2008) proposing the use of organic geochemical proxies as a new tool in paleotempestology. It should be noted, however, that different proxies detect different aspects of a hurricane's impacts and have different sensitivity thresholds to hurricane impact magnitudes. Thus the organic geochemical record and the overwash sedimentary record from Lake Shelby cannot be directly compared, let alone using one as a standard 
to falsify the other. More important, a critical issue in the reconstructed paleohurricane record of Lambert et al. (2008) concerns its radiocarbon chronology, which was obtained by subtracting 927 ${ }^{14} \mathrm{C}$ yr from the conventional ${ }^{14} \mathrm{C}$ ages measured from bulk organic samples. An alternative interpretation would be to accept the $840 \pm 40$ ${ }^{14} \mathrm{C}$ yr BP at $12.0 \mathrm{~cm}$ but reject the anomalous date of $875 \pm 40{ }^{14} \mathrm{C} \mathrm{yr} \mathrm{BP}$ obtained at the core top, which could be contaminated by redeposition of older materials due to human activities (e.g., construction) around Lake Shelby.

In conclusion, we welcome critical comments of our work by other researchers; that is part of the process by which science advances. However, to be useful, such criticisms must be well grounded on recent literature and must go beyond issues that had already been addressed in previous discussions. During the past decade, paleotempestology has become a burgeoning scientific field marked by increasing sophistication in theory and methodology (Liu, 2004, 2007b; Nott, 2004). It has also attracted public attention (which Otvos perceives as "sensation") because of its relevance to policy-makers and society. Otvos is oblivious to these recent advances in paleotempestology and ignores replies (Liu and Fearn, 2002; Liu, 2004, 2007a) to his previous critiques. His letter is also fraught with conceptual confusion and even misreading of the literature that he is criticizing.

\section{References}

Bianchette, T., 2007. Using Hurricane Ivan as a modern analog in paleotempestology: lake sediment studies and environmental analysis in Gulf Shores, Alabama. M.S. Thesis, Louisiana State University, $125 \mathrm{p}$.

Donnelly, J.P., 2005. Evidence of past intense tropical cyclones from backbarrier salt pond sediments: a case study from Isla de Culebrita, Puerto Rico, USA. Journal of Coastal Research SI42, 201-210.

Donnelly, J.P., Webb, III, T., 2004. Backbarrier sedimentary records of intense hurricane landfalls in the northeastern United States. In: Murnane, R.J., Liu, K.-b. (Eds.), Hurricanes and Typhoons: Past, Present, and Future. Columbia University Press, New York, pp. 58-96.

Donnelly, J.P., Woodruff, J.D., 2007. Intense hurricane activity over the past 5,000 years controlled by El Niño and the West African Monsoon. Nature 447, 465-468.

Donnelly, J.P., Bryant, S.S., Butler, J., Dowling, J., Fan, L., Hausmann, N., Newby, P., Shuman, B., Stern, J., Westover, K., Webb, III, T., 2001a. A 700 yr sedimentary record of intense hurricane landfalls in southern New England. Geological Society of America Bulletin 113, 714-727.

Donnelly, J.P., Roll, S., Wengren, M., Butler, J., Lederer, R., Webb, III, T., 2001b. Sedimentary evidence of intense hurricane strikes from New Jersey. Geology 29, 615-618.

Donnelly, J.P., Butler, J., Roll, S., Wengren, M., Webb, III, T., 2004. A backbarrier overwash record of intense storms from Brigantine, New Jersey. Marine Geology 210, 107-121.

Elsner, J.B., Jagger, T.H., Liu, K.-b., 2008. Comparison of hurricane return levels using historical and geological records. Journal of Applied Meteorology and Climatology 47, 368-374.
Lambert, W.J., Aharon, P., Rodriguez, A.V., 2008. Catastrophic hurricane history revealed by organic geochemical proxies in coastal lake sediments: a case study of Lake Shelby, Alabama (USA). Journal of Paleolimnology 39, 117-131.

Liu, K.-b., 2004. Paleotempestology: principles, methods, and examples from Gulf coast lake-sediments. In: Murnane, R., Liu, K.-b. (Eds.), Hurricanes and Typhoons: Past, Present, and Future. Columbia University Press, New York, pp. 13-57.

Liu, K.-b., 2007a. Uncovering prehistoric hurricane activity. American Scientist 95, 126-133.

Liu, K.-b., 2007b. Paleotempestology. In: Elias, S.A. (Ed.), Encyclopedia of Quaternary Science. Elsevier, Oxford, pp. 1978-1986.

Liu, K.-b., Fearn, M.L., 1993. Lake-sediment record of late Holocene hurricane activities from coastal Alabama. Geology 21, 793-796.

Liu, K.-b., Fearn, M.L., 2000. Reconstruction of prehistoric landfall frequencies of catastrophic hurricanes in NW Florida from lake sediment records. Quaternary Research 54, 238-245.

Liu, K.-b., Fearn, M.L., 2002. Lake sediment evidence of coastal geologic evolution and hurricane history from Western Lake, Florida: reply to Otvos. Quaternary Research 57, 429-431.

Liu, K.-b., Lu, H.Y., Shen, C.M., 2008. A 1,200-year proxy record of hurricanes and fires from the Gulf of Mexico coast: testing the hypothesis of hurricane-fire interactions. Quaternary Research 69, 29-41.

Lu, H.Y., Liu, K.-b., 2005. Phytolith indicators of coastal environmental changes and hurricane overwash deposition. The Holocene 15, 965-972.

Nott, J., 2004. Palaeotempestology: the study of prehistoric tropical cyclones-a review and implications for hazard assessment. Environment International 30, 433-447.

Otvos, E.G., 1999. Quaternary coastal history, basin geometry and assumed evidence for hurricane activity, northeastern Gulf of Mexico coastal plain. Journal of Coastal Research 15, 438-443.

Otvos, E.G., 2002. Discussion of "Prehistoric landfall frequencies of catastrophic hurricanes..." (Liu and Fearn, 2000). Quaternary Research 57, 425-428.

Scileppi, E., Donnelly, J.P., 2007. Sedimentary evidence of hurricane strikes in western Long Island, New York. Geochemistry, Geophysics, Geosystems 8, Q06011, doi:10.1029/2006GC001463.

Woodruff, J.D., Donnelly, J.P., Mohrig, D., Geyer, W.R., 2008. Reconstructing relative flooding intensities responsible for hurricane-induced deposits from Laguna Playa Grande, Vieques, Puerto Rico. Geology 36, 391-394.

Kam-biu Liu

Department of Oceanography and Coastal Sciences,

School of the Coast and Environment, Louisiana State University,

Baton Rouge, LA 70803, USA

E-mail address: kliu1@lsu.edu. Corresponding author.

Houyuan Lu

Institute of Geology and Geophysics, Chinese Academy of Sciences, Beijing 100029, China

Caiming Shen Atmospheric Sciences Research Center, University at Albany, SUNY, Albany, NY 12203, USA

22 October 2008 